\title{
A INTERDISCIPLINARIEDADE NA EDUCAÇÃO AMBIENTAL COMO INSTRUMENTO PARA A CONSOLIDAÇÃO DO DESENVOLVIMENTO SUSTENTÁVEL
}

Odacir Miguel Tagliapietra ${ }^{1}$

Irene Carniatto ${ }^{2}$

Resumo: A relação homem/natureza vem se alterando ao longo dos tempos. Inicialmente, existia uma relação harmônica, pois o ser humano extraia da natureza somente o necessário para sua sobrevivência, mas com o aumento da população e os avanços tecnológicos, houve cada vez mais o predomínio do homem sobre a natureza e tal decisão gera desequilíbrio nos ecossistemas. Para reverter esse quadro foram realizadas diversas conferências, encontros e ações visando à busca de um novo modelo de desenvolvimento que minimizasse os impactos socioambientais ocasionados pela racionalidade econômica vigente. A Educação Ambiental surge como uma tentativa de se desenvolver uma mentalidade crítica e reflexiva, ligada à integração das diversas ciências, a partir de uma abordagem interdisciplinar. Esse tipo de interação entre os diversos saberes visa tratar os problemas socioambientais em sua totalidade e complexidade. $\mathrm{O}$ conceito de sustentabilidade envolve aspectos econômicos e socioambientais. Nesse sentido, é necessário que haja o envolvimento das diversas ciências em uma perspectiva interdisciplinar. Desta maneira, será possível o desenvolvimento que atenda a todos os aspectos da realidade para que se mantenha 0 ambiente natural com toda sua vitalidade com equidade e justiça social. O estudo se caracteriza como bibliográfico, cujo objetivo é analisar a importância da interdisciplinaridade para a consolidação do desenvolvimento sustentável. Como resultado, pode-se concluir que, conforme analisado na literatura pesquisada, o desenvolvimento sustentável somente se efetiva a partir de uma visão sistêmica do desenvolvimento, alicerçado no tripé econômico, social e ambiental, para tanto necessita de uma abordagem interdisciplinar com a contribuição dos diferentes tipos de saberes.

Palavras-chave: Sustentabilidade; Interdisciplinaridade; Educação Ambiental; Natureza.

${ }^{1}$ Universidade Estadual do Oeste do Paraná. E-mail: odacir.tagliapietra@unioeste.br

2 Universidade Estadual do Oeste do Paraná. E-mail: irenecarniatto@gmail.com. 


\section{Introdução}

A relação do homem com a natureza era, inicialmente, harmônica. Havia interação positiva com o meio ambiente, posto que o homem não interferia naquele de maneira indiscriminada, logo, 0 equilíbrio dos ecossistemas era mantido. No entanto, com o crescimento populacional, o surgimento dos mercados e os avanços tecnológicos, intensificou-se a interferência do homem sobre a natureza e, por conseguinte, o rompimento na relação de equilíbrio homem/natureza. Durante a evolução das civilizações, a interação dos seres humanos com a natureza vem se distanciando cada vez mais. Percebe-se que o primeiro passa a assumir uma posição de domínio sobre os demais seres vivos.

A crise ecológica que se presencia é resultado da indiferença humana com a natureza, caraterizada pela busca do desenvolvimento econômico negligenciando os aspectos socioambientais. Nesse sentido, a Educação Ambiental surge com o objetivo de promover a educação em relação à necessidade da preservação dos recursos naturais visando tanto a sua sustentabilidade como a uma tentativa de se reverter o quadro de destruição e descaso com a natureza, a partir do desenvolvimento de uma nova consciência voltada para o desenvolvimento sustentável.

A Educação Ambiental (EA) e Educação para o Desenvolvimento Sustentável (EDS) são complementares. De acordo com Branco, Linard e Sousa (2011), desenvolvimento sustentável é o conceito mais abrangente que envolve uma educação relacionada aos aspectos socioambientais e políticos, o qual dá ênfase às culturas locais, preocupa-se com a pobreza e o bem-estar da população. A EA trata das relações entre homem e natureza e preocupa-se com a preservação dos recursos naturais.

Tanto a EA como o EDS necessitam de uma abordagem interdisciplinar, pois envolvem vários aspectos da realidade. As interações entre homem, natureza e sociedade fazem parte das abordagens de uma educação para o desenvolvimento sustentável. Nessa complexidade de interações estão aspectos relacionados aos seres vivos, às dimensões voltadas para a cultura, aos conhecimentos e às formas de organização da sociedade, entre outros. Assim, o objetivo desse trabalho foi analisar a interdisciplinaridade na Educação Ambiental como instrumento para a consolidação do desenvolvimento sustentável. Para isso, foi realizada uma pesquisa bibliográfica.

$\mathrm{Na}$ primeira parte do artigo foram apresentados conceitos sobre a relação homem/natureza, com destaque para essa interação. Inicialmente, ela ocorreu de forma harmoniosa, mas com o decorrer do tempo, devido ao crescimento da polução e à utilização de instrumentos tecnológicos, houve uma predominância do homem sobre a natureza, a qual afetou o ciclo natural de renovação dos ecossistemas. 
$\mathrm{Na}$ segunda parte desta pesquisa, o destaque foi para a Educação Ambiental, quando se demonstrou a importância da educação para 0 desenvolvimento de uma nova consciência que visa ao surgimento de uma nova racionalidade voltada para a reconstrução da relação harmoniosa entre homem e natureza.

$\mathrm{Na}$ terceira parte, destacou-se a interdisciplinaridade da Educação Ambiental. Nesse sentido, a educação deve ser voltada para a valorização de todos os saberes, pois o conceito de sustentabilidade envolve todos os aspectos da realidade, ou seja, ambiental, social e econômico.

$\mathrm{Na}$ quarta parte tratou-se sobre o desenvolvimento sustentável como um conceito interdisciplinar que visa à integração dos aspectos socioambientais e econômicos e, por último, as considerações finais.

\section{Relação Sociedade, Homem e Natureza}

A relação homem/natureza tem mudado com o tempo. Inicialmente, os indivíduos eram organizados em grupo e retiravam da natureza somente o que necessitavam para a sua sobrevivência. Eles organizavam o espaço de vida de acordo com a produção, a qual atendia as suas necessidades e desejos. Com o tempo e o início do comércio, das novas necessidades e desejos, essa relação foi se alterando, bem como a organização da sociedade e do espaço (SANTOS, 1992).

Ainda segundo o autor, o processo de apropriação da natureza iniciase nos tempos em que o homem começava a esboçar as primeiras técnicas para auxiliar as atividades de extração dos recursos naturais para sua sobrevivência. A criação dos primeiros instrumentos representou a primeira tentativa de "domesticação das plantas e animais". O surgimento da agricultura também contribui para o início dos desmatamentos. No entanto, apesar de os homens tentarem dominar a natureza com auxílio de instrumentos, inicialmente, devido a sua precariedade, não interferia no ciclo natural com isso, havia a manutenção e o funcionamento de todos os ecossistemas, tendo em vista que, por exemplo, uma área desmatada não era cultivada subsequentemente.

No passado, os homens utilizavam os recursos naturais na concepção de que eram abundantes e se renovavam permanentemente. Mas com o aumento da população e do consumo visualizou-se a possibilidade de seu esgotamento em face da utilização em grande quantidade, com isso, não se permitia que o processo de renovação completasse seu ciclo (BRANDALISE; BERTOLINI; HOSS; ROJO, 2017). Nesse sentido, para Charlot e Silva (2005, p. 69), "a natureza é resultado das intervenções coletivas dos homens, não sendo, portanto, eterna e imutável'.

Para Leandro (2008), a natureza, quando cultivada, é resultado das diversas formas de atuação do homem. Assim, estão envolvidos aspectos relacionados à cultura bem como os hábitos de determinado grupo, a maneira 
de utilização da terra - a partir das técnicas utilizadas e dos tipos de produção e consumo da população. Tudo isso fez com que se estabelecesse o ordenamento dos campos, das florestas e dos rios, cujo resultado foi a criação das paisagens de acordo com cada época. Nesse sentido, "os tipos de organizações sociais são resultantes não somente das relações entre indivíduos e grupos, mas também da forma como se apropriam dos recursos da natureza" (OLIVEIRA, 2000, p. 82).

De acordo com Leff (2002, p. 79),

O potencial ambiental de uma região não está determinado tãosomente por sua estrutura ecossistêmica, mas pelos processos produtivos que nela desenvolvem diferentes formações socioeconômicas. As práticas de uso dos recursos dependem do sistema de valores das comunidades, da significação cultural de seus recursos, da lógica social e ecológica de suas práticas produtivas e de sua capacidade para assimilar estes conhecimentos científicos e técnicos modernos. Assim, o vínculo sociedade natureza deve ser entendido como uma relação dinâmica, que depende da articulação histórica dos processos tecnológicos e culturais que especificam as relações sociais de produção de uma formação socioeconômica, bem como a forma particular de desenvolvimento integrado ou de degradação destrutivas de suas forças produtivas.

Portanto, as relações do homem com a natureza são dependentes de cada época, cujos fatores determinantes são as necessidades de sobrevivência, a cultura predominante, a forma de organização da sociedade, entre outros. As mudanças na relação do homem com a natureza podem estar relacionadas com o uso de tecnologias, aumento da população, forma de organização das comunidades e as políticas adotadas pelos países.

Para Silva; Mercedes e Araújo (2014), a relação homem, natureza e sociedade não é harmoniosa, já que consiste em uma relação utilitária, que visa à exploração econômica e ocasiona danos ao meio ambiente e à saúde das pessoas. Além disso, o crescimento de maneira desordenada dos espaços urbanos tem contribuído para o surgimento de impactos socioambientais.

$\mathrm{Na}$ medida em que, falando de meio ambiente, são colocadas no centro das preocupações as relações entre as sociedades humanas e o meio físico-natural que elas ocupam e exploram, o ser humano não pode mais ser considerado como "hóspede" do meio que habita. Ele apresenta-se necessariamente como parte integrante desse meio, do qual é, ao mesmo tempo, sujeito e objeto, ator e produto (RAYNAUT, 2004, p. 28). 
Diante desse cenário, busca-se cada vez mais, através da educação, disseminar uma nova consciência voltada para o restabelecimento de uma interação positiva entre os seres humanos e a natureza, visando ao desenvolvimento sustentável, para que o Planeta seja preservado com todos os seus recursos e atenda às necessidades das gerações presente e futura.

A educação, como um processo reflexivo sobre a interação dos seres humanos com a natureza e com seus semelhantes, tem a função de estabelecer uma nova racionalidade voltada para 0 desenvolvimento sustentável. A partir da aprendizagem de novos conceitos, é possível o desenvolvimento de mudanças para a reaproximação entre os seres humanos e a natureza. O novo paradigma deve buscar a equidade dessa relação e descontruir a visão hegemônica que estabelece a supremacia dos seres humanos aos demais seres vivos.

\section{Enfoque da Educação Ambiental}

A educação em seu sentido amplo é um processo de aprendizagem que visa à incorporação de novos conceitos às experiências de cada indivíduo, proporcionando mudanças de comportamentos para 0 alcance de determinados objetivos e a adequação destes às normas da sociedade. No entanto, não se pode confundir educação com adestramento em que se impõem certos conceitos, de maneira impositiva, sem a existência do diálogo. A educação pressupõe um comportamento alicerçado na ética, pois estabelece regras para a boa convivência em sociedade.

Para Maturana (1998), a educação ocorre a partir da convivência com o outro. Dessa maneira, o aprendizado acontece na medida em que o modo de vida de uma pessoa converge para o modo de convivência de determinado grupo. Nesse sentido, o educar é um processo de contínua adaptação das pessoas ao modo de conviver de determinada comunidade.

Nessa perspectiva, a Educação Ambiental, como parte do conceito amplo de educação, busca o desenvolvimento de uma nova consciência em relação aos problemas socioambientais, o qual somente é possível em uma sociedade onde exista justiça social.

Para Brandalise et al. (2017), a Educação Ambiental deve ser um processo que estimule o desenvolvimento da consciência crítica, sobre as questões ambientais, nas interações com a sociedade visando à preservação ecológica.

Medina (2002) também ressalta a necessidade de a Educação Ambiental possuir uma postura crítica e capaz de contribuir para o esclarecimento dos valores predominantes da sociedade, bem como permitir mudanças de atitudes, que possibilitem a adoção de um caráter participativo em relação às questões relacionadas à conservação e à preservação dos recursos naturais. Ainda, segundo o autor, o objetivo primordial da Educação 
Ambiental é a busca pela "melhoria na qualidade de vida e a eliminação da pobreza extrema e do consumismo desenfreado".

A Educação Ambiental deve ser crítica e inovadora em todos os seus níveis, sejam eles formais ou informais. Nesse sentido, deve ser um ato político direcionado para a transformação social. Ainda, segundo o autor, a educação deve ser holística e capaz de envolver homem, natureza e universo tendo como preocupação a preservação dos recursos naturais. Nesse tripé da concepção holística, o homem é o principal responsável pela degradação do meio ambiente (JACOBI, 2003).

Medina (2002) destaca a importância da Educação Ambiental para a melhoria da qualidade de vida das pessoas, pois a partir do processo participativo, os indivíduos desenvolvem novos valores sociais e éticos, adquirem novas habilidades e conhecimentos sobre como manter um ambiente ecologicamente equilibrado para o bem comum das gerações presentes e futuras.

De acordo com Barbieri (2006), a Educação Ambiental deve-se apresentar numa nova ética universal, tendo em vista que os problemas socioambientais são globais. Essa nova postura deve estimular mudanças de hábitos das pessoas e ser portadora de soluções e não apenas de denúncias. No entanto, diante do agravamento dos problemas socioambientais, as denúncias devem continuar sendo a primeira alternativa para conter as agressões à vida humana e ao meio ambiente.

Travassos (2004) destaca a importância de uma Educação Ambiental que enfatiza os aspectos práticos, os quais devem desenvolver conceitos comuns na sociedade e sensibilizar os membros a adotarem práticas de preservação do meio ambiente onde vivem. Com o entendimento comum sobre práticas de preservação do meio ambiente, as pessoas participarão mais e estarão mais comprometidas em torno dessa causa.

Uma educação voltada para a ecologia deve sair da teoria, do ambiente restrito dos estudos acadêmicos e voltar-se para a experiência. $O$ educando deve vivenciar e presenciar a realidade, entrar em contato com a natureza, conhecer um pouco da história das paisagens e dos diferentes tipos de relevos com seus rios e toda sua biodiversidade (BOFF, 2016).

A Educação Ambiental deve permitir a formação de indivíduos que sejam capazes de enfrentar a racionalidade dominante. Essas pessoas devem projetar um novo cenário, onde seja possível a convivência harmônica entre homem e natureza. Essa nova racionalidade deve permitir a superação das crises social e ambiental, ocasionadas pela racionalidade econômica e instrumental (MEDINA; SANTOS, 1999).

Para Sauvé (1997), a Educação Ambiental tem ficado restrita aos problemas ecológicos e à proteção do ambiente natural, pois não há uma preocupação com seu entorno, ou com as necessidades dos povos que fazem parte do ambiente. $\mathrm{O}$ ecossistema é composto pelo ambiente natural e pelos 
indivíduos que habitam determinado espaço e por isso deve-se buscar uma educação que considere as necessidades e os direitos das populações que fazem parte do ambiente.

Nesse sentido, é fundamental o desenvolvimento de uma educação integradora, que, além de desenvolver uma nova consciência, se preocupe com a realidade das populações que vivem em situação de pobreza extrema. Nesse sentido, novas oportunidades de trabalho são necessárias, a fim de que supram as necessidades básicas para a sobrevivência humana. Uma educação que visa à sustentabilidade deve estimular a preservação dos recursos naturais e, ao mesmo tempo, oportunizar melhoria na qualidade de vida das pessoas.

Sato (2001) se posiciona de maneira crítica às publicações na área de Educação Ambiental na medida em que apresenta apenas os resultados favoráveis, dando a falsa impressão de que esse tema possui linearidade, mas não apresentam obstáculos, dificultando com isso o fortalecimento da EA. Ainda, as ações realizadas relacionam-se às

ações pontuais de abraçar árvores ou oficinas de reciclagem de papel, sem nenhuma postura crítica dos modelos de consumo vivenciados pelas sociedades, ou pela análise do modo de relação dominadora do ser humano sobre a natureza, com alto valor antropocêntrico (...) as indústrias fazem campanhas nas escolas, através de jogos competitivos e não solidários, para a coleta de "latinhas" de alumínio, enquanto incentivam mais consumo para a premiação de computadores e de outros materiais escolares. Estudantes plantam árvores no dia mundial do meio ambiente (5 de junho), como se o ambientalismo se resumisse em datas comemorativas e não se configurasse como um projeto de vida, de lutas sociais para os cuidados ecológicos, necessários para a construção da sociedade que queremos (SATO, 2001, p. 16).

A crise ecológica é uma preocupação planetária, resultante de um paradigma econômico que homogeneizou as relações entre homem e a natureza. Por isso, a superação dessa crise requer mudanças de paradigmas para que se estabeleçam novas relações visando à construção de uma nova ordem ambiental, social e econômica (SOLER; DIAS, 2016).

Para Jacobi (2003), é necessário que se incrementem os meios de comunicação, como promotores e locais de acesso para educação e destaquem a importância do papel do Estado na promoção de conteúdos educacionais voltados para o desenvolvimento de uma nova consciência socioambiental. Conforme o autor, para que as pessoas possam se tornar agentes de transformação para as mudanças requeridas e os problemas socioambientais, faz-se necessário que elas tenham participação nas decisões para "fortalecer sua corresponsabilidade na fiscalização e no controle dos agentes de degradação ambiental". 
A postura de dependência e de desresponsabilização da população decorre principalmente da desinformação, da falta de consciência ambiental e de um déficit de práticas comunitárias baseadas na participação e no envolvimento dos cidadãos, que proponham uma nova cultura de direitos baseada na motivação e na coparticipação da gestão ambiental (JACOBI, 2003, p. 192).

A educação socioambiental deve ser participativa, para que as pessoas possam desenvolver uma consciência ambiental e serem responsáveis pelas ações necessárias a fim de se evitar a degradação ambiental e na busca de soluções para os problemas sociais.

A Educação Ambiental é um instrumento imprescindível para a consolidação dos novos modelos de desenvolvimento sustentável, com justiça social, visando à melhoria da qualidade de vida das populações envolvidas, em seus aspectos formais e não formais, como processo participativo através do qual o indivíduo e a comunidade constroem novos valores sociais e éticos, adquirem conhecimentos, atitudes, competências e habilidades voltadas para o cumprimento do direito a um ambiente ecologicamente equilibrado em prol do bem comum das gerações presentes e futuras (MEDINA, 2002, p. 52).

\section{Interdisciplinaridade na Educação Ambiental}

Segundo Raynaut (2004), o enfoque interdisciplinar tem como desafio resgatar a percepção de totalidade e a complexidade do mundo no qual vivemos. Os questionamentos sobre fronteiras e limites do conhecimento não são próprios do mundo real, mas resultados de representações de uma realidade construída.

O mundo real, na sua essência, é total. Ele é feito de interações múltiplas e complexas entre os muitos elementos que o compõem, não conhecendo ou admitindo fronteiras estanques. Essa totalidade do mundo, sua unicidade, as correspondências entre os elementos que o compõem constituíram um dos primeiros modos de construção da consciência do universo pelo pensamento humano e da concepção da posição do homem nele. Muitas foram e são as maneiras de afirmar e tentar apreender essa unicidade. É o caso do pensamento mítico, de várias correntes filosóficas e das religiões que submetem toda a Criação à vontade unificadora de um Deus único (RAYNAUT, 2004, p. 25).

A interdisciplinaridade está relacionada à forma de organização do conhecimento, ao invés de analisar os fenômenos de maneira fragmentada. Assim, busca-se produzir conhecimento a partir da complexidade e da 
interdependência dos fenômenos que fazem parte do complexo da natureza (CARVALHO, 1998).

De acordo com Leão e Silva (1999), a Educação Ambiental faz parte da educação, pois incorpora a questão ambiental em uma realidade interdisciplinar e analisa as questões ambientais locais em termos globais. A Educação Ambiental deve estimular a consciência crítica, envolver todos os setores da sociedade na preservação dos recursos naturais para 0 bem-estar socioeconômico da sociedade.

Os saberes compartimentados, utilizados nas práticas de ensino tradicional, tornam os indivíduos alienados. Nessa perspectiva, a educação tem a função de domesticação e serve como uma espécie de adestramento, ou seja, não proporciona educação crítica nem participativa. A realidade hoje necessita de uma educação que estimule a conexão entre as diversas partes da realidade. Essa interação é fundamental para a construção de uma sociedade sustentável (BODNAR; FREITAS; SILVA, 2016).

A multiplicidade de saberes deve ser inserida no estudo e na construção de uma Educação Ambiental voltada para o desenvolvimento sustentável. As diversas formas de aprendizagem, de linguagens, de conceitos (tais como convivência, manejo, preservação, direitos, deveres e custos sociais) de contextos históricos, políticos e sociais devem ser levados em consideração na elaboração e efetivação da prática educativa, valorizando experiências e saberes individuais e coletivos (BRANCO; LINARD; SOUSA, 2011, p. 29).

A ciência ecológica compreende toda a cadeia de relações na biosfera, incluindo os seres humanos, que transformam e são transformados pelas condições naturais. Nesse sentido, fazem parte da ciência ecológica, além da natureza, os seres humanos e todas suas manifestações a partir da cultura e na sua forma de organização em sociedade (CARVALHO, 1998).

Segundo Floriani (2000), uma agenda socioambiental deve partir de uma perspectiva interdisciplinar e estabelecer uma aliança entre as "ciências da vida, da natureza e da sociedade", resultando em nova postura dos seres humanos no seu convívio em sociedade e com a natureza.

Nesse sentido, segundo Sachs (2009, p. 31-32),

necessitamos, portanto, de uma abordagem holística e interdisciplinar, na qual cientistas naturais e sociais trabalhem juntos em favor do alcance de caminhos sábios para o uso e aproveitamento dos recursos da natureza, respeitando a sua diversidade. Conservação e aproveitamento racional da natureza podem e devem andar juntos. 
Para fazer frente aos desafios socioambientais, a Educação Ambiental surge com o objetivo de romper com o paradigma dominante que instalou tipos de saberes baseados em uma linearidade disciplinar. Assim, a Educação Ambiental surge para questionar o conhecimento e estabelecer um novo saber para o desenvolvimento de uma nova racionalidade (RODRIGUES; NASCIMENTO, 2017).

Parece haver um consenso na literatura sobre Educação Ambiental quanto ao seu desenvolvimento de forma não disciplinar. Os documentos oficiais e a produção dos mais diversos autores sobre o tema preconizam uma Educação Ambiental de forma transversal ao currículo, a ser trabalhada, especialmente, de forma inter ou transdisciplinar, ou apontando outras formas, sempre na perspectiva de romper com os limites disciplinares (RODRIGUES; NASCIMENTO, 2017, p. 160).

Deve-se, portanto, analisar a integração dos diversos campos de saberes para se entender a problemática ambiental, onde se convergem processos naturais e sociais (LEFF, 2002).

Leandro (2008) destaca que falar sobre Educação Ambiental está associado a todo o Planeta. Isso envolve a complexidade de relações que se estabelecem entre os seres e os demais componentes que fazem parte do mundo. Portanto, para a compreensão das relações existentes entre os diversos componentes que formam a intrigada rede de relações, é necessário o envolvimento das diversas ciências, seja ela, ciência da natureza ou das áreas sociais como filosofia, psicologia, antropologia, entre outras.

As ciências sociais e naturais estão convocadas juntamente com as outras expressões de produção social do conhecimento, para esse colóquio, em nova parceria, para tentar desatar muitos nós que nos prendem a visões e a práticas limitadas de relacionamento entre os seres humanos em sociedade e com a natureza. Tornar um mundo viável e não apenas possível, eis o grande desafio para os que começam a perceber que fazer ciência, em novas bases, é menos complicado do que parece, mas é mais complexo do que efetivamente se apresenta (FLORIANI, 2000, p. 37).

\section{Desenvolvimento Sustentável}

O termo desenvolvimento foi amplamente discutido pelos estudiosos tendo em vista as diversas intepretações. O conceito de desenvolvimento foi considerado sinônimo de crescimento econômico. Com essa associação, denominavam-se economias desenvolvidas aquelas que apresentam grande crescimento econômico associado ao PIB (produto interno bruto). Em contraposição a essa forma de análise, a partir de pesquisas, apesar do 
elevado crescimento econômico, determinados países apresentavam diversos problemas sociais, como pobreza e grande disparidade na distribuição de renda. A partir disso, o critério para a classificação do grau de desenvolvimento, que utilizava a renda per capita como índice de avaliação, foi alterado para o IDH (índice de desenvolvimento Humano).

Este índice inclui três dimensões básicas de desenvolvimento: longevidade (viver uma vida longa e saudável), conhecimento (ser instruído) e padrão de vida (gozar de um nível de vida adequado). A partir daí foram criadas três variáveis para medir o desenvolvimento humano em diferentes países: esperança de vida, nível educacional (alfabetização de adultos e escolaridade nos três níveis) e PIB real per capita (SANTOS 2001, p. 226).

Para Malheiros et al (2013), a sustentabilidade deve ser tratada na perspectiva interdisciplinar, tendo em vista que o homem inserido na sociedade influencia nos sistemas ecológicos e esses, por sua vez, afetam a forma de desenvolvimento das sociedades.

Em 1977, a Conferência Intergovernamental sobre Educação Ambiental foi realizada em Tbilisi (EUA) onde se estabeleceu, em nível global, as condições para o desenvolvimento de uma nova consciência sobre a importância da preservação da natureza e, também tratou sobre a importância da produção do conhecimento baseada nos "métodos da interdisciplinaridade e nos princípios da complexidade" (JACOBI, 2003).

No entanto, foi em 2002, na Rio+10, realizada em Johanesburgo, que o conceito de sustentabilidade, além da dimensão global, assumiu um conceito, mais amplo incluindo as perspectivas ecológicas, social e econômica. A partir disso, a inclusão da dimensão social tornou-se fundamental em qualquer projeto de desenvolvimento, pois não é possível desenvolver uma consciência sobre o cuidado com o meio ambiente sem justiça social (BODNAR; FREITAS; SILVA, 2016).

Assim, a ideia de sustentabilidade implica a prevalência da premissa de que é preciso definir limites às possibilidades de crescimento e delinear um conjunto de iniciativas que levem em conta a existência de interlocutores e participantes sociais relevantes e ativos por meio de práticas educativas e de um processo de diálogo informado, o que reforça um sentimento de corresponsabilidade e de constituição de valores éticos. Isto também implica que uma política de desenvolvimento para uma sociedade sustentável não pode ignorar nem as dimensões culturais, nem as relações de poder existentes e muito menos 0 reconhecimento das limitações ecológicas, sob pena de apenas manter um padrão predatório de desenvolvimento (JACOBI, 2003, p. 195). 
De acordo com Leff (2010), a nova economia, fundamentada nos pilares da sustentabilidade, visa a uma política de convivência na diversidade, de respeito aos outros e à natureza. $O$ processo de diferenciação permite abrir o curso do conhecimento e dos saberes descontruindo a racionalidade das ciências que visa unificar o conhecimento.

O que reabre a história é a pluralidade das identidades e das formas de ser em relação com o saber. A interdisciplinaridade deve gerar um espaço de articulação das ciências, mas deve transcender para uma hibridação entre as disciplinas científicas, os saberes acadêmicos e os saberes populares (LEFF, 2010, p. 33).

Boff (2016) apresenta a definição de sustentabilidade em uma perspectiva holística e ressalta a importância da preservação do Planeta Terra, onde se devem considerar os fatores físico-químico e humano, ou seja, a preservação do meio ambiente para que as gerações presentes e futuras possam desfrutar de todas as suas potencialidades nas diversas formas de expressão.

Boff (2012) faz uma ressalva ao conceito clássico de sustentabilidade desenvolvido pela ONU do Relatório Brundtland (1987), tendo em vista que no conceito: "Desenvolvimento sustentável é aquele que atende as necessidades das gerações atuais sem comprometer a capacidade das gerações futuras de atenderem às suas necessidades e aspirações", considera apenas os seres humanos, é um conceito "antropocêntrico", pois desconsidera os demais seres vivos que também necessitam da biosfera para sobrevivência. No artigo "Sustentabilidade: tentativa de definição", publicado no site do Jornal do Brasil em 2012, Boff apresenta um conceito mais integrador sobre sustentabilidade.

Sustentabilidade é toda ação destinada a manter as condições energéticas, informacionais e físico-químicas que sustentam todos os seres, especialmente a Terra viva, a comunidade de vida e a vida humana, visando a sua continuidade e ainda a atender as necessidades da geração presente e das futuras de tal forma que o capital natural seja mantido e enriquecido em sua capacidade de regeneração, reprodução e coevolução.

Para Leff (2015), o processo de desenvolvimento tem como princípio a sustentabilidade e requer que a visão fragmentada das realidades seja conciliada em prol do desenvolvimento local, a partir da articulação desses mercados com os mercados globais. As oposições características da racionalidade da globalização mostram-se incompatíveis ao crescimento econômico e à preservação do meio ambiente, à articulação entre urbano e rural e à preservação do patrimônio cultural. Em contrapartida, o 
desenvolvimento sustentável visa mostrar que a articulação entre essas visões opostas é compatível, ou seja, é possível o crescimento econômico concomitantemente com a preservação do meio ambiente e a manutenção da identidade cultural de determinada comunidade. A sustentabilidade não está baseada em uma economia de retrocesso, não busca a economia de subsistência, mas busca "integrar as populações locais num mundo diverso e sustentável" (LEFF, 2015, p. 61). Ainda, segundo o autor, o discurso da sustentabilidade busca reconciliar os contrários da dialética do desenvolvimento: o meio ambiente e o desenvolvimento econômico.

O princípio de sustentabilidade surge como uma resposta à fratura da razão modernizadora e como uma condição para construir uma nova racionalidade produtiva, fundada no potencial ecológico e em novos sentidos de civilização a partir da diversidade cultural do gênero humano. Trata-se da reapropriação da natureza e da reinvenção do mundo; não só de "um mundo o qual caibam muitos mundos", mas de um mundo conformado por uma diversidade de mundos, abrindo o cerco da ordem econômico-ecológica globalizada (LEFF, 2015, p. 31).

\section{Conclusões}

O desenvolvimento sustentável está atrelado à busca de uma nova racionalidade alicerçada no tripé econômico e socioambiental. A racionalidade dominante, que prioriza o desenvolvimento econômico em detrimento dos aspectos socioambientais, trata a natureza de maneira fragmentada a partir de uma visão disciplinar, em que as diversas ciências atuam separadamente sem considerar a perspectiva sistêmica da natureza. Nesse sentido, é preciso adotar uma nova perspectiva para atuação das ciências onde, a partir da abordagem interdisciplinar, as diversas disciplinas possam se comunicar a fim de se analisar a natureza.

No que tange os problemas ambientes, devem-se analisar os seres humanos em seus aspectos culturais, nas características de determinada comunidade, em seus anseios e necessidades. O estabelecimento de uma interação harmônica entre os seres humanos e a natureza possibilitará maior cooperação entre as pessoas com a busca da preservação do meio ambiente e com o desenvolvimento de sociedade mais justa e igualitária.

A postura crítica da Educação Ambiental proporciona a criação de atitudes diante da falta de cuidado com o meio ambiente e com os problemas sociais, que cada vez mais se agravam. A crise global tem se intensificado nos últimos anos, tendo em vista a prevalência do desenvolvimento econômico nas bases do sistema capitalista, onde a concentração do capital e dos lucros está restrita a uma pequena minoria, em detrimento da grande parte da população em situação de extrema pobreza. Por isso, uma educação crítica e participativa

revista brasileira educação ambiental 
torna-se um instrumento para o desenvolvimento de uma sociedade sustentável proporcionando com isso, a preservação do meio ambiente e oportunizando melhoria na qualidade de vida da população.

Nesse sentido, é importante uma educação que valorize a integração de todos os saberes em uma perspectiva interdisciplinar, pois a fragmentação da realidade não é capaz de atender à complexidade da realidade. $O$ conceito de desenvolvimento sustentável integra todos os aspectos da realidade. Logo, representa uma nova racionalidade que busca o desenvolvimento da sociedade com equidade e justiça social.

Não é possível falar em estratégia para preservação do meio ambiente nem em implantação de ações para melhoria de áreas degradadas se a população afetada se encontra em situação precária tanto econômica como socialmente. Por isso, o desenvolvimento sustentável, a partir da perspectiva interdisciplinar, busca atender a todos os aspectos da realidade, nos âmbitos local, regional e global.

\section{Referências}

ALMEIDA, M.I.S. A emergência da Educação Ambiental no cenário mundial: evolução dos conceitos e concepções da Educação Ambiental. Boletim Goiano de Geografia. Goiânia, v. 20, n. 1, p. 19-42, jan./dez. 2000.

BODNAR, Z.; FREITAS, V.P.; SILVA, K.C. A epistemologia interdisciplinar da sustentabilidade: por uma ecologia integral para a sustentação da casa comum. Revista Brasileira de Direito. Passo Fundo, v.12, n. 2, p. 59-70, jul./dez. 2016.

BOFF, L. Sustentabilidade: o que é: o que não é. $5^{\mathrm{a}}$ ed. Petrópolis-RJ: Vozes, 2016.

BRANCO, A.F.V.C.; LINARD, Z.U.S.A.; SOUSA, A.C.B. Educação para o desenvolvimento sustentável e Educação Ambiental. Conexões - Ciência e Tecnologia. Fortaleza, v. 5, n. 1, p. 25-31, mar. 2011.

BRANDALISE, L.T.; BERTOLINI, G.R.F.; HOSS, O.; ROJO, C.A. A. Educação e gestão ambiental: sustentabilidade em ambientes competitivos. $2^{\underline{a}}$ ed. Cascavel, Paraná: DRHS, 2017.

BRÜGGER, P. Educação ou adestramento ambiental? Letras Contemporâneas, 1999.

BUENO, R.L.; ARRUDA, R.A. Educação Ambiental. Revista Eventos Pedagógicos. Sinop, v.4, n.2, p. 182 - 190, ago./dez. 2013.

CALEGARE, M.G.A.; JÚNIOR, N.S. Inter e/ou transdisciplinaridade como condição ao estudo de questões socioambientais. R. Inter. Interdisc. INTERthesis. Florianópolis, v.9, n.2, p.216-245, jul./dez. 2012. 
CARVALHO, I.C.M. Em direção ao mundo da vida: interdisciplinaridade e Educação Ambiental / Conceitos para se fazer Educação Ambiental. Brasília: IPÊ - Instituto de Pesquisas Ecológicas, 1998.

CASTELNOU, A.M.N; FLORIANI, D.; VARGAS, I.A.; DIAS, J.B. Sustentabilidade socioambiental e diálogo de saberes: o Pantanal Matogrossense e seu espaço vernáculo como referência. Desenvolvimento e Meio Ambiente. Curitiba, n. 7, p. 41-67, jan./jun. 2003.

CHARLOT, B.; SILVA, V.A. Relação com a natureza e Educação Ambiental. In: SATO, Michele; CARVALHO, Isabel Cristina Moura (Org.). Educação Ambiental: pesquisas e desafios. Porto Alegre: Artmed, 2005.

FLORIANI, D. Diálogos interdisciplinares para uma agenda socioambiental: breve inventário do debate sobre ciência, sociedade e natureza. Desenvolvimento e Meio Ambientes. Curitiba, n. 1, p. 21-39, jan./jun. 2000.

JACOBI, P. Educação Ambiental, cidadania e sustentabilidade. Cadernos de Pesquisa. São Paulo, n. 118, p. 189-205, març. 2003.

JACOBI, P.; LUZZI, D. Educação e meio ambiente - um diálogo em ação. São Paulo, 2004. Disponível em: http://www.luzimarteixeira.com.br/wpcontent/uploads/2011/04/educacao-e-meio-ambiente.pdf. Acesso em: $12 \mathrm{dez}$. 2017.

LEANDRO, Z.F. Ecopsicologia - um conceito em construção e a dimensão da Educação Ambiental: horizontes para a recuperação do "perdido elo" com a natureza. In: MEDEIROS, Dalva Helena de (Org.). Relação Homem/Natureza sob a ótica da Interdisciplinaridade. Campo Mourão, Editora da FECILCAM, 2008.

LEFF, E. Saber ambiental: sustentabilidade, racionalidade, complexidade, poder. $11^{\text {a }}$ ed. Petrópolis, RJ: Vozes, 2015.

LEFF, E. Discursos sustentáveis. São Paulo: Cortez, 2010.

LEFF, E. Epistemologia ambiental. 2ª ed. São Paulo: Cortez, 2002.

LEÃO, A.L.C.; SILVA, L.M.A. Fazendo Educação Ambiental. 4aㅡ ed. Recife: CPRH - Companhia Pernambucana do Meio Ambiente, 1999.

MALHEIROS, T.F.; PÉREZ, M.A.; SAMPAIO, C.A.C.; ZUÑIGA, C.H. RBPG. Brasília, v. 10, n. 21, p. 537 - 552, out. 2013.

MATURANA R., H. Emoções e linguagem na educação e na política. Belo Horizonte: Ed. UFMG, 1998.

MEDINA, N.M.; SANTOS, E.C. Educação Ambiental: uma metodologia participativa de formação. Petrópolis - SP: Vozes, 1999.

MEDINA, N.M. Formação de multiplicadores para Educação Ambiental. In: PEDRINI, A.G. (Org.). O Contrato Social da Ciência, unindo saberes na Educação Ambiental. Petrópolis: Vozes, 2002, p. 47-70. 
MEDEIROS, D.H. Imaginário e simbolismo nas crianças da comunidade da bacia do Rio do Campo. In: MEDEIROS, D.H. (Org.). Relação Homem/Natureza sob a ótica da Interdisciplinaridade. Campo Mourão - PR: Editora da FECILCAM, 2008.

OLIVEIRA, E.M. Educação Ambiental: uma possível abordagem. Brasília: Ibama, 2000.

PHILIPPI JR, A.; SOBRAL, M.C.; FERNANDES, V. Desenvolvimento sustentável, interdisciplinaridade e Ciências Ambientais. RBPG. Brasília, v. 10, n. 21, p. 509 - 533, out. 2013.

RAYNAUT, C. Os desafios contemporâneos da produção do conhecimento: o apelo para interdisciplinaridade. R. Inter. Interdisc. INTERthesis. Florianópolis, v.11, n.1, p. 1-22, Jan./Jun. 2014.

RAYNAUT, C. Meio ambiente e desenvolvimento: construindo um novo campo do saber a partir da perspectiva interdisciplinar. Desenvolvimento e Meio ambientes. Curitiba, n. 10, p. 21-32, jul./dez. 2004. Editora UFPR.

RODRIGUES, J.C.R.; NASCIMENTO, R.Silva. Complexidade e Educação Ambiental. Revbea. São Paulo, v.11, n. 5, p.152-165, 2017.

SATO, M. Debatendo os desafios da Educação Ambiental. 2001. Disponível em: $\quad$ http://nead.uesc.br/arquivos/Biologia/bsc1/artigo1 Debatendo os desafios da ed ambiental.pdf. Acesso em: 12 de jul. 2018.

SANTOS, M. O Brasil: território e sociedade no início do século XXI. 13 ed. Rio de Janeiro: Record, 2000.

SANTOS, M. 1992: A redescoberta da Natureza. São Paulo: Estudos Avançados, São Paulo, v.6, n.14, jan./abr. 1992.

SAUVÉ. Educação Ambiental e desenvolvimento sustentável: uma análise complexa. 1997.

Disponível em:<http://www.serrano.neves.nom.br/MBA GYN/edsoc10.pdf >. Acesso em: 12 jul. 2018.

SILVA, B.S.M.; MERCES, M.C.; ARAÚJO, T.M. Interface entre saúde, ambiente e trabalho na ótica da sustentabilidade. Rev Epidemiol Control Infect. Santa Cruz do Sul, V. 4, n.2, p. 65-170, abr./jun. 2014.

SOLER, A.; DIAS, E.A. A Educação Ambiental na crise ecológica Contemporânea. Acesso Livre, Pelotas, n. 5, p. 146-164, jan./jun. 2016.

TRAVASSOS, E.G. A prática da Educação Ambiental nas escolas. Porto Alegre: Mediação, 2004. 